ARTIGO

\title{
FINANCIAMENTO PÚBLICO (FIES E PROUNI) PARA O ENSINO DE MEDICINA NO BRASIL: UMA REVISÃO DA LITERATURA E AS DISTORÇÕES CRIADAS
}

\author{
LEONARDO MASO NASSAR ${ }^{1}$ \\ ORCID: https://orcid.org/0000-0002-4300-4293 \\ MARIA HELENA DA COSTA COUTO ${ }^{2}$ \\ ORCID: https://orcid.org/0000-0001-6636-9124 \\ GERSON ALVES PEREIRA JÚNIOR ${ }^{3}$ \\ ORCID: https://orcid.org/0000-0003-3920-3000
}

\begin{abstract}
RESUMO: As pressões da sociedade, após a expansão do ensino superior privado, resultou na criação do FIES e do PROUNI. Com o aumento do número de novas escolas de Medicina em decorrência da Lei do Programa Mais Médicos, novas pressões poderão ocorrer por conta de vagas ociosas, inadimplência dos estudantes ou redução dos incentivos govervanemtais. O objetivo deste artigo é mapear os estudos acerca do financiamento estudantil para o ensino superior no Brasil e realizar uma discussão relacionando os achados com a situação da graduação de medicina no Brasil. Utilizou-se como método a Scooping review do Joanna Briggs Institute com os descritores: financiamento governamental, privatização e instituições acadêmicas. 134 artigos foram encontrados para uma seleção final de 11 trabalhos. Os resultados evidenciaram a importância do auxílio governamental para a organizações privadas de ensino, incentivando a expansão do segmento. Para o ensino de Medicina, a expansão privada é motivo de alerta pela qualidade questionável de muitas instituições.
\end{abstract}

Palavras-chave: financiamento governamental, ensino de medicina, instituições acadêmicas, FIES, PROUNI.

\section{PUBLIC FUNDING (FIES AND PROUNI) FOR THE MEDICAL EDUCATION IN BRAZIL: A LITERATURE REVIEW AND THE DISTORTIONS CREATED}

\footnotetext{
ABSTRACT: Pressure from society, following the expansion of private higher education, resulted in the creation of FIES and PROUNI. With the increase in the number of new medical schools as a result of the More Doctors Program Law, new pressures may occur due to vacant seats, student default, or the reduction of government incentives. The objective of this article is to map the studies on student

1 Faculdade de Economia, Administração e Contabilidade de Ribeirão Preto (FEA-RP), Ribeirão Preto, SP, Brasil. $<$ leo.mnassar@gmail.com>.

${ }^{2}$ Universidade do Estado do Rio de Janeiro (UERJ), Rio de Janeiro, RJ, Brasil. < costacoutomh@gmail.com>

${ }^{3}$ Universidade de São Paulo (USP), Bauru, SP, Brasil. <gersonapj@gmail.com> 
financing for higher education in Brazil and to conduct a discussion relating the findings to the situation of undergraduate medical education in Brazil. The method used was the Scooping review of the Joanna Briggs Institute with the descriptors: government financing, privatization and academic institutions. 134 articles were found for a final selection of 11 papers. The results showed the importance of government aid for private educational organizations, encouraging the expansion of the segment. For medical education, private expansion is a cause for concern due to the questionable quality of many institutions.

Keywords: government funding, medical education, academic institutions, FIES, PROUNI.

\section{FINANCIAMIENTO PÚBLICO (FIES Y PROUNI) PARA LA EDUCACIÓN MÉDICA EN BRASIL: UNA REVISIÓN DE LA LITERATURA Y LAS DISTORSIONES CREADAS}

RESUMEN: Las presiones de la sociedad, con la expansión de la educación superior privada, resultaran en la creación del FIES y PROUNI. Con el aumento del número de nuevas escuelas de medicina como resultado del Programa Más Médicos, pueden surgir nuevas presiones debido a vacantes, incumplimiento de estudiantes o reducción de incentivos gubernamentales. El objetive es mapear los estudios sobre financiamiento de estudiantes para la educación superior en Brasil y realizar una discusión relacionando los hallazgos con la situación del pregrado en medicina en Brasil. El método fue revisión de scooping del Instituto Joanna Briggs, con mnemónico PCC, siendo financiamiento gubernamental para la población; privatización, por concepto, e instituciones académicas, por contexto. Se encontraron 134 artículos para una selección final de 11 trabajos. Los resultados mostraron la importancia de la ayuda gubernamental para las organizaciones educativas privadas, fomentando la expansión del segmento. Para la educación médica, la expansión de la red privada es motivo de advertencia por la cuestionable calidad de muchas instituciones.

Palabras clave: Financiamiento gubernamental, Medicina de la educación, Universidades, FIES, PROUNI. 


\section{INTRODUÇÃO}

Os cursos de Medicina são muito procurados nos vestibulares nacionais, o que justifica, em parte, a expansão atual tanto do número de escolas médicas (342, um aumento de 48,2\% nos últimos 10 anos) quanto de vagas para graduandos de $1^{\circ}$ ano (35.388), que representou um aumento de $40,2 \%$ no mesmo período. Do total de cursos médicos, se considerados os cursos que cobram mensalidades, há 1877 vagas de graduação, sendo $64,9 \%$ dos cursos e 73,8\% das vagas na iniciativa privada (ESCOLAS MÉDICAS DO BRASIL, 2020).

O curso de Medicina tem duração de seis anos. Durante esse período, os estudantes lidam com uma ampla carga horária de disciplinas teóricas e práticas em currículos tradicionais, híbridos ou com maior uso de metodologias ativas de ensino aprendizagem. Além das aulas em laboratórios, os estudantes passam por estágios supervisionados por docentes e preceptores em hospitais, ambulatórios e unidades de saúde. Na grande maioria das vezes, esses estágios são viabilizados por meio de convênios com as instituições de saúde, principalmente as privadas. A estrutura necessária para um curso dessa amplitude influencia no valor das mensalidades. Esse é um dos motivos para o valor da mensalidade de Medicina ser o mais alto entre os cursos de graduação das instituições privadas brasileiras. Apesar do preço variar de uma instituição para outra, a mensalidade de medicina oscila entre $\mathrm{R} \$ 5$ mil e $\mathrm{R} \$ 12$ mil (ESCOLAS MÉDICAS DO BRASIL, 2020).

O ensino de graduação em Medicina vem sofrendo mudanças nos últimos anos em decorrência de alterações éticas no uso de animais para ensino, dificuldades na obtenção de cadáveres e a crescente incorporação tecnológica de manequins morfofuncionais, plataformas virtuais e simuladores de diferentes complexidades, obrigando as instituições a adotarem métodos alternativos de ensino com alto custo (BRANDÃO; CARVALHO-FILHO; CECÍLIO-FERNANDES, 2018).

Isso pode representar um potencial comprometimento dos lucros, e disso decorrem pressões da iniciativa privada à União, como já ocorreu no passado (CHAVES; AMARAL, 2016). Pressionado tanto pelas famílias, impossibilitadas de pagarem as mensalidades, como pelas Instituições de Ensino Superior Privadas (IESP), pela inadimplência dos matriculados e vagas ociosas, o governo foi obrigado a agir e a tomar providências para atenuar as pressões recebidas pela sociedade (CHAVES; AMARAL, 2016).

As soluções encontradas pelo governo, ao mesmo tempo em que buscaram reduzir investimentos nas universidades federais, consistiram em estimular o pagamento de mensalidades e bolsas permanência aos estudantes por meio de isenções tributárias às IESP por meio do Programa Universidade para Todos (PROUNI), isenção do pagamento do salário-educação, empréstimos financeiros para estudantes carentes por meio do Fundo de Financiamento ao Estudante de Ensino Superior (FIES), empréstimos financeiros a juros subsidiados pelo Banco Nacional de Desenvolvimento Econômico e Social (BNDES), entre outras medidas com recursos federais, provocando uma dependência do setor privado junto ao governo (CHAVES, 2015).

O FIES foi criado por meio da Medida Provisória $n^{0}$ 1.827, de 27 de maio de 1999, transformada na Lei no 10.260, de 12 de julho de 2001 (BRASIL, 2001). De acordo com o texto da lei, o FIES é destinado à concessão de financiamento a estudantes regularmente matriculados em cursos superiores não gratuitos que possuem avaliação positiva do MEC.

O PROUNI foi criado em 2004 com o objetivo de conceder bolsas de estudos integrais e parciais para estudantes do ensino superior privado, sendo concedida isenção fiscal pelo governo federal para as instituições participantes (BRASIL, 2005).

O FIES, diferentemente do PROUNI, não representa uma transferência de recursos públicos para o setor privado, pois se trata de um empréstimo bancário a ser devolvido pelo estudante após a conclusão do curso (PINTO, 2016).

$\mathrm{O}$ alto custo do ensino médico, juntamente com as restrições governamentais impostas pela Emenda Constitucional no 95 (BRASIL, 2016) podem prejudicar os lucros das IESP, comprometendo a qualidade da formação do futuro médico pela opção das instituições de incorporarem tecnologias diversificadas ou pela redução de custos, como substituição de professores mais experientes.

Com o aumento no número de cursos de Medicina nos últimos anos, principalmente no setor privado, há uma preocupação com a qualidade do ensino médico nacional provocada pelo aumento 
dos custos educacionais e com a capacidade das IESP de gerenciarem essa situação (NASSAR; PEREIRA JÚNIOR, 2019). Os crescentes custos da graduação médica atrelam a manutenção da qualidade do ensino com a expansão da receita da IESP, que precisariam ou aumentar o número de vagas de graduação, ou elevar os valores da mensalidade, ou cortar custo educacionais, ou reorganizar processos (NASSAR; PEREIRA JÚNIOR, 2019). Em um cenário de expansão semelhante ao ocorrido até os anos 90, é possível acreditar que novas pressões sociais, como as ocorridas no passado, voltem a acontecer (CHAVES; AMARAL, 2016).

Em um contexto de restrições financeiras e aumento no custo do ensino de medicina, emerge a pergunta norteadora da pesquisa: qual a literatura produzida sobre financiamento estudantil governamental para o ensino superior brasileiro e os impactos futuros para o ensino de Medicina no Brasil?

Para responder à pergunta, foi realizada uma revisão integrativa da literatura com o objetivo de mapear os estudos acerca do financiamento estudantil para o ensino superior no Brasil. Em seguida, foi feita uma discussão relacionando os achados com o ensino de medicina e os desdobramentos que ocorreram.

\section{METODOLOGIA}

Para realizar a revisão, foi utilizado a mnemônica População, Conceito e Contexto (PCC) para a abordagem Scoping Review do Joanna Briggs Institute (JBI), uma organização internacional sem fins lucrativos que compõe a School of Translational Science of Faculty of Health Science, University of Adelaide na Austrália (JBI, 2019).

Dentre os contextos, "População" refere-se à população ou a um problema que pode ser um indivíduo ou um grupo em uma condição específica; "Conceito" pode ser todos os elementos detalhados e relevantes a serem considerados; "Contexto" é determinado segundo o objetivo e a pergunta da revisão, sendo definido pelos fatores culturais. Para a pergunta norteadora do presente estudo, foram definidos os seguintes descritores controlados do Descritores em Ciências da Saúde (DeCS):

- População: financiamento governamental;

- Conceito: privatização;

- Contexto: instituições acadêmicas.

Os descritores controlados e não-controlados do Medical Subject Heading (MeSH) também foram utilizados. Para complementar as buscar, fez-se uso das seguintes palavras-chave: FIES, Prouni, expansão privada, expansão, private expansion, expansion, Brazil, Brazilian e Brazilians. Também foram considerados os termos booleanos junto aos descritores: AND, OR e NOT.

Quanto à estratégia de busca, foram consultadas seis bases de dados: Scientific Eletronic Library Online (SciELO), Literatura Latino-Americana e do Caribe em Ciências da Saúde (LILACS), PubMed, Cochrane, Scopus e Web of Science. Não houve limitação amostral pela data de publicação dos artigos a fim de encontrar a maior quantidade de trabalhos disponíveis sobre o assunto.

A pesquisa e seleção bibliográfica foi realizada por pares durante o mês de agosto de 2020, guiada por um roteiro elaborado pelos autores com os critérios de elegibilidade: artigos completos disponíveis; artigos disponíveis nos idiomas português, inglês ou espanhol; artigos completos que respondessem à pergunta norteadora do estudo. Com relação ao recorte temporal, optou-se por utilizar todo o período disponível nas bases para obtenção de uma quantidade maior de trabalhos. Os artigos foram selecionados com a utilização do software Start.

\section{RESULTADOS}

A busca resultou em um total de 134 trabalhos. Inicialmente, foram excluídos os trabalhos duplicados da amostra para, na sequência, iniciar o processo de leitura dos títulos, dos resumos e dos conteúdos dos artigos, sempre com a aplicação dos critérios de elegibilidade. Caso houvesse dúvidas quanto à exclusão de trabalho, ele era aprovado na etapa e reanalisado na fase seguinte do processo de 
seleção. Após a aplicação dos critérios de elegibilidade foram selecionados 11 artigos científicos. O processo de seleção e o resultado da revisão encontram-se descritos na Figura 1.

Figura 1 - Processo de seleção dos artigos.

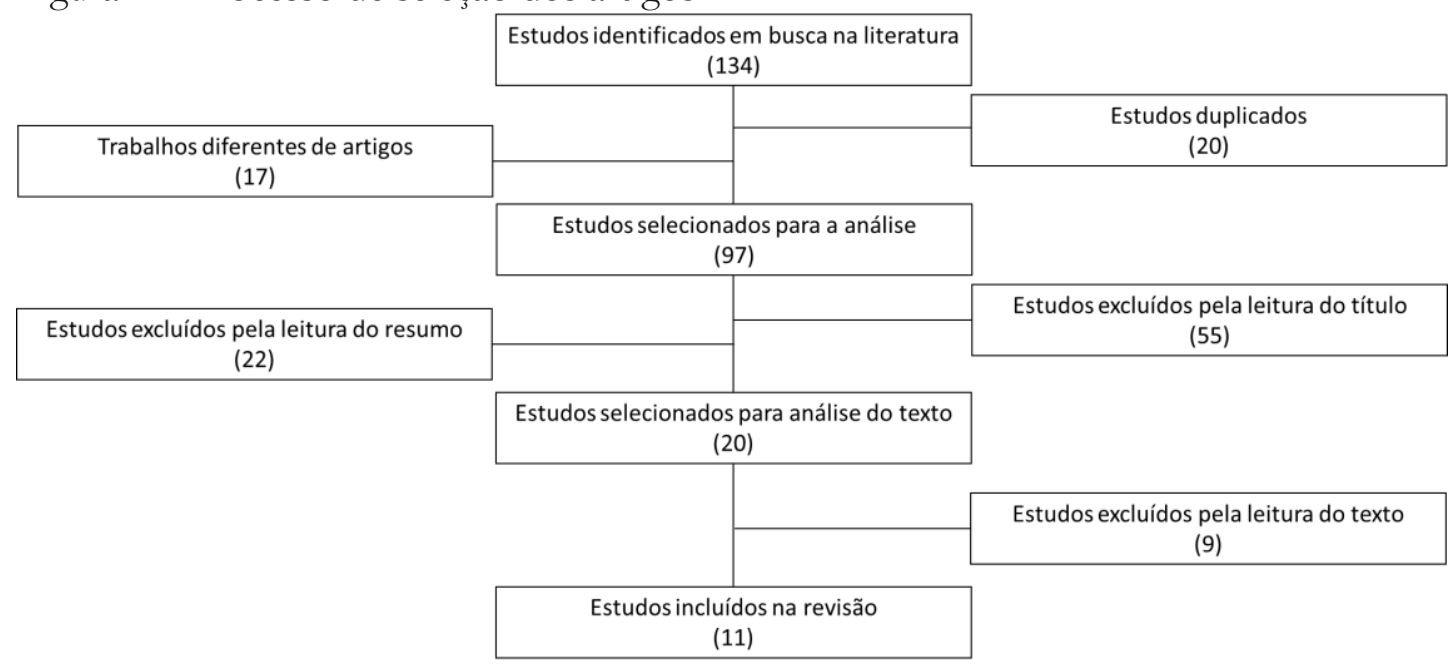

Fonte: Elaborado pelos autores.

Na Tabela 1, é possível identificar os autores, os títulos, os objetivos e os anos de publicação dos trabalhos.

Tabela 1 - Principais informações dos artigos científicos selecionados para o estudo.

Autor

$\begin{array}{ll} & \text { O PROUNI no governo } \\ \text { Carvalho (2006) } & \begin{array}{l}\text { Lula e o jogo político em } \\ \text { torno do acesso a ensino } \\ \text { superior. }\end{array}\end{array}$

Expansion without equity:

McCowan (2007)

Souza; Menezes
(2014)

Chaves (2015)

Pinto (2016)
An analysis of current policy on access tohigher education in Brazi

Programa Universidade Identificar quais atores ganharam o quê, para Todos (PROUNI): quem ganha o quê, como e quando?

Política de financiamento e a expansão da educação superior no Brasil: o público e o privado em questão.

Uma análise da destinação dos recursos públicos, direta ou indiretamente, ao setor privado de ensino no Brasil.

\section{Objetivo}

Ano

Compreender a relação complexa e dinâmica da política pública para o ensino superior no governo Lula, no que tange ao PROUNI e sua articulação com a política fiscal e o financiamento por meio da renúncia tributária.

Desenvolver um conceito de equidade no ensino superior quando e como, a partir do processo político desenvolvido durante a formulação do programa.

Analisar o perfil do financiamento para a expansão do ensino superior, visando discutir a parceria público-privada para tanto, nos governos de Lula da Silva e Dilma Rousseff.

Analisar os diferentes mecanismos de repasse de recursos públicos ao setor privado de ensino, bem como os valores envolvidos. 
Política de expansão da Analisar a política de expansão da educação superior no Brasil educação superior brasileira no período

\begin{tabular}{|c|c|c|}
\hline $\begin{array}{l}\text { Chaves; } \\
\text { (2016) }\end{array}$ & Amaral & $\begin{array}{l}\text { educação superior no Brasil } \\
\text { - o PROUNI e o FIES } \\
\text { como financiadores do } \\
\text { setor privado. }\end{array}$ \\
\hline $\begin{array}{l}\text { Dal Poz; } \\
\text { Franco (2016) }\end{array}$ & Couto; & $\begin{array}{l}\text { Inovação, } \\
\text { desenvolvimento } \\
\text { financiamento } \\
\text { instituições de Ensir } \\
\text { Superior em saúde. }\end{array}$ \\
\hline
\end{tabular}

$\begin{array}{lll}\text { Costa; } & \text { Ferreira } & \begin{array}{l}\text { O PROUNI na educação } \\ \text { superior } \\ \text { indicadores de acesso e } \\ \text { permanência. }\end{array}\end{array}$

$\begin{array}{ll} & \text { Programa Universidade } \\ \text { Haas; Pardo (2017) } & \text { eara Todos (PROUNI): } \\ & \text { efeitos financeiros em uma } \\ & \text { instituição de educação } \\ & \text { superior privada. }\end{array}$

A expansão da educação superior privada no Brasil por meio do FIES

$\begin{array}{llr} & \begin{array}{l}\text { Política pública } \\ \text { governamental: um estudo }\end{array} \\ \text { acerca do programa } \\ \text { universidade para todos - } \\ \text { PROUNI de 2005 a } 2018\end{array}$

2003-2014, tendo como ênfase a análise do PROUNI e FIES como financiadores do setor privado.

Analisar a configuração e as tendências e das instituições de Ensino Superior de saúde no seu relacionamento enquanto componentes do Complexo Econômico Industrial da Saúde (CEIS). Avaliar em que medida o PROUNI expande o acesso à Educação Superior, identificando as condições de ingresso, matrícula, custo-estudante e permanência por meio do Índice de Conclusão de Curso, numa escala nacional.

Verificar se a isenção fiscal alcançada por uma IESP com fins lucrativos, após adesão ao PROUNI, superou os investimentos em bolsas de estudos ofertadas pelo programa.

Discutir como o financiamento do governo federal foi importante tanto para a expansão quanto para o crescimento dos grupos empresariais de educação superior privada no Brasil, entre a segunda metade dos anos 1990 à primeira década do século XXI.

Realizar um estudo bibliográfico e documental sobre o ProUni enquanto política pública para expansão do 2019 ensino superior.

Fonte: elaborado pelos autores.

Carvalho (2006) analisou as condições de acesso dos estudantes mais pobres ao PROUNI em busca do diploma de graduação. Segundo a autora, desde a Reforma Universitária de 1968 ocorreu no Brasil uma expansão do ensino privado até um esgotamento no número de novos estudantes, provocando incertezas no setor devido ao elevado número de vagas ociosas. A busca do acesso ao diploma fundamentou a proposta do MEC de estatizar vagas em IESP em troca de incentivos fiscais como forma de resposta às pressões políticas de grupos educacionais, deixando subentendida a influência do setor na política de ensino nacional (CARVALHO, 2006).

As instituições mais beneficiadas pelo programa à época foram as mais lucrativas, com regras mais flexíveis e com maior ganho relativo em renúncia fiscal. O texto legal foi evoluindo para a direção do afrouxamento do aparato estatal, desregulamentando sanções mais severas ao descumprimento de regras e estimulando atitudes oportunistas de IESP de qualidade duvidosa. O resultado foi uma maioria dos estudantes beneficiados pelo programa estudando em instituições de ensino com baixa qualidade (CARVALHO, 2006).

Para elaborar seu conceito de equidade no ensino superior, McCowan (2007) abordou as principais políticas públicas brasileiras para a educação superior, incluindo incentivos para os alunos das universidades públicas, com as quotas, e estudantes de cursos privados, mencionando o FIES e o 
PROUNI. Sobre o FIES como forma de equidade no ensino superior, o autor argumenta que havia uma série de problemas com essa abordagem para resolver o problema da equidade no longo prazo, devido ao mau funcionamento do sistema no contexto brasileiro e às limitações inerentes a um sistema de empréstimos (MCCOWAN, 2007). Sobre o PROUNI, McCowan (2007) apresenta a forte oposição ao plano por parte de professores universitários, reitores e estudantes e seus respectivos sindicatos, que acreditavam que o dinheiro gasto (que foi deixado de ser arrecadado) seria mais bem aplicado nas universidades públicas, ocorrendo também oposição de algumas IESP.

O autor, entretanto, acredita que a eficiência do PROUNI é boa, pois as vagas ociosas das universidades são preenchidas, a iniciativa não traria altos custos para o Estado, pois as IESP pagam pouco imposto, mantendo o crescimento vertiginoso do setor privado em relação ao público (MCCOWAN, 2007). Com relação ao FIES, o autor foi crítico ao argumentar que o incentivo só estava disponível para estudantes se o empréstimo fosse garantido por um fiador com uma receita duas vezes maior do que o total das taxas, limitando o benefício apenas aqueles com alguma medida de segurança financeira poderiam obter um empréstimo (MCCOWAN, 2007). Por fim, conclui que intervenções governamentais, como o FIES e o PROUNI, podem aumentar o acesso para estudantes de baixa renda, mas o fazem de forma limitada e não podem ser a base de uma política de longo prazo bem-sucedida (MCCOWAN, 2007).

O artigo de Souza e Menezes (2014) buscou identificar os atores envolvidos no processo político de reformulação do PROUNI e os ganhos obtidos por cada um. Segundo os autores, o segmento privado foi o maior beneficiado pela política do PROUNI, pois conseguiram influenciar o governo a definir mecanismos de implementação do programa em contexto onde as taxas de ociosidade das vagas estavam superiores a 740 mil, como resultado da Reforma Universitária de 1968. A influência dos atores privatistas na formulação do PROUNI tornou o programa mais próximo das demandas da IESP do que das necessidades do público-alvo original (SOUZA; MENEZES, 2014).

As IESP apresentaram êxito em modificar todas as regras que lhes trariam benefícios, reduzindo a quantidade de bolsas disponíveis e os controles institucionais, mantendo a supressão das alíquotas do Imposto Sobre a Renda de Pessoas Jurídicas (IFPJ), Contribuição Social Sobre Lucro Líquido (CSLL), Programa de Integração Social (PIS) e Contribuição Para Financiamento da Seguridade Social (CONFINS) (SOUZA; MENEZES, 2014). Na ausência de mecanismos de fiscalização eficientes para obtenção da renúncia de arrecadação, o sistema torna-se mais permissivo com a falta de qualidade de várias IESP, que geralmente apresentam grandes deficiências pedagógicas, resultando em um processo educativo de baixa qualidade. Ademais, os autores destacam que o objetivo de várias IESP é o lucro e, consequentemente, os dividendos aos acionistas, sem perspectiva de reduzi-los para investir em qualidade de ensino (SOUZA; MENEZES, 2014).

O estudo de Chaves (2015) fez uma reflexão sobre a política de financiamento da educação superior brasileira, partindo da tese de que tal financiamento está diretamente relacionado à política de ajustes fiscal do Estado. Com a política de contingenciamento de recursos para garantir superávit primário e sinalizar aos credores as boas intenções governamentais em economizar, o governo reduziu os investimentos no ensino superior público e incentivou a expansão do ensino superior pelo setor privado com incentivos estatais como o FIES e o PROUNI (CHAVES, 2015).

O trabalho de Pinto (2016) analisou diferentes formas de repasse governamental para o setor privado de ensino, entre eles o FIES e o PROUNI, representando 56\% de todo o gasto federal com manutenção e desenvolvimento do ensino no ano de 2014. Ao analisar a Constituição Federal de 1988, o autor destaca que a transferência de recursos para IESP de ensino de caráter lucrativo é inconstitucional e, a concessão de bolsas de estudo deveria passar por regulamentação. No caso do PROUNI, Pinto (2016) destaca que o programa se configura como uma compra de vagas pelo governo federal na rede privada lucrativa, violando o art. 213 da Constituição Federal que permite a destinação de recursos públicos apenas para as IESP não lucrativas.

A criação dos PROUNI foi interessante para o governo federal da época porque o aproximou de um setor que lhe era geralmente crítico, mas também foi um excelente negócio para o setor privado que passaria a ter uma remuneração, apesar de indireta, pela ocupação das vagas ociosas (PINTO, 2016). O FIES também se apresentou como um excelente negócio para o setor privado, pois 
o total de contratos correspondeu, no ano de 2014, a 35\% das matrículas da rede privada de ensino superior. Parte significativa do ônus do pagamento desses recursos caberá à sociedade, pois vários estudantes estão recebendo ensino de baixa qualidade, com diplomas de baixa acreditação junto ao mercado e, num cenário de recessão econômica, as condições para arcarem com o pagamento do empréstimo realizado serão mínimas, ocasionando inadimplência (PINTO, 2016).

O artigo de Chaves e Amaral (2016) analisou documentos governamentais para levantar dados financeiros e educacionais, constatando que a expansão do ensino superior ocorreu, tanto pela via pública como pela via privada. Entretanto, a maior parcela da expansão ocorreu pelo setor privado, principalmente entre os anos de 1995 e 2014, obtendo 74,9\% dos estudantes matriculados em 2014 (CHAVES, AMARAL, 2016). Em especial, o setor privado recebeu incentivos governamentais por meio do PROUNI e FIES e, apesar da ressalva a ser feita pelo fato do FIES ser um empréstimo, ele aumenta a dívida pública da União e, historicamente, tais tipos de transação trazem alto índice de inadimplência (CHAVES; AMARAL, 2016).

Os autores afirmam que os volumes dos recursos associados ao PROUNI e ao FIES contribuem de forma fundamental para o aumento das matrículas no setor privado, colaborando para a obtenção de lucro e a oferta de uma educação superior que dissocia o ensino de graduação da pesquisa e da extensão (CHAVES; AMARAL, 2016).

O estudo de Dal Poz, Couto e Franco (2016) abordou a expansão do ensino superior como parte da transição de sistemas de elite para sistemas de massa que faz parte de fenômenos como a globalização, transformações econômicas, surgimentos de novas tecnologias de comunicação e a emergência de uma rede internacional de conhecimento, refletindo em possíveis impactos na formação em saúde. Devido aos desafios no campo dos recursos humanos enfrentados pelos sistemas de saúde, a Organização Mundial da Saúde (OMS) e outras agências indicaram a necessidade de os estados nacionais investirem em formação de pessoal para atuar na área de saúde (DAL POZ; COUTO; FRANCO, 2016). Os autores destacam que o aumento da exigência tecnológica nos sistemas de saúde não é acompanhado pelo ensino onde, no contexto brasileiro, há uma divisão entre poucas instituições de excelência acadêmica no eixo Sul e Sudeste e várias instituições com dificuldades de obter padrões mínimos de exigência para o ensino e incapazes de realizar pesquisa e extensão, sendo que $36 \%$ dos cursos privados obtiveram conceito 1 ou 2 no Exame Nacional de Desempenho dos Estudantes (ENADE) frente a 4,5\% dos cursos públicos no ano de 2013 (DAL POZ; COUTO; FRANCO, 2016).

A expansão do ensino privado, estimulada por incentivos governamentais, não foi acompanhada por mecanismos regulatórios eficazes para garantir a qualidade do ensino e reduzir os desequilíbrios entre oferta e demanda no mercado de trabalho em saúde e as desigualdades geográficas existentes. As formas de regulamentação do ensino superior enfrentam dificuldades por conta da ampliação do mercado privado que aumentou a competitividade, alterou os processos de formação do profissional e criou novos desafios para as políticas públicas (DAL POZ; COUTO; FRANCO, 2016).

O estudo de Costa e Ferreira (2017) utilizou dados governamentais para estimar informações sobre os impactos do PROUNI. De acordo com os autores, o PROUNI foi responsável por um aumento médio de 5,25\% no número de matrículas no setor privado ao ano, representando um custo-estudante anual médio de $\mathrm{R} \$ 3.381,43 /$ anual ou $\mathrm{R} \$ 281,78 /$ mês por bolsista e uma ociosidade média de $30 \%$ e a evasão foi na ordem de 10,4\%, provavelmente em função das restrições econômicas dos estudantes (COSTA; FERREIRA, 2017). Verificou-se que o PROUNI propicia o preenchimento de vagas ociosas das IESP, proporciona isenção fiscal às instituições e encaminha estudantes para cursos menos concorridos que sequer poderiam ingressar em uma IESP. Segundo os autores, as análises revelaram limitações do programa em controlar a ocupação das bolsas destinadas entre 2005 e 2009, permanecendo em 2012 quando regulamentações já existiam (COSTA; FERREIRA, 2017). Mesmo com as bolsas ociosas, as IESP permaneciam isentas de forma integral dos tributos previstos em lei (COSTA; FERREIRA, 2017). Os autores demonstram preocupação com a situação porque recursos deixaram de ser arrecadados pelo Estado, representando desperdícios sociais, acadêmicos e econômicos de recursos investidos sem retorno (COSTA; FERREIRA, 2017).

O artigo de Haas e Pardo (2017) investigou documentos contábeis de uma IESP para demonstrar que o ganho fiscal alcançado pela instituição, após sua adesão ao PROUNI, foi superior aos 
investimentos destinados em bolsas de estudos e contribuiu financeiramente para a estabilização e manutenção do crescimento institucional ao longo dos anos. O valor total das bolsas, entre 2008 e 2010 , representou para a IESP um investimento de $\mathrm{R} \$ 286.462,00$, representando um ganho de $\mathrm{R} \$ 927.862,00$ que, em termos percentuais representa 424\% (HAAS; PARDO, 2017). Segundo os autores, a IESP deixou de arrecadar para os cofres da União um montante de $\mathrm{R} \$ 1.214 .323,00$ referente aos impostos federais no período estudado (HAAS; PARDO, 2017).

O artigo de Pereira e Brito (2018) buscou mostrar os benefícios do FIES para a rede privada do ensino superior, utilizando o exemplo do grupo União das Instituições Educacionais do Estado de São Paulo (UNIESP), possuindo cerca de 77\% dos 130 mil alunos beneficiados pelo programa em 2013. $\mathrm{O}$ artigo trouxe uma crítica sobre a forma como o FIES transformou, por intermédio do governo federal, o indivíduo, no caso, o estudante, em uma mercadoria (PEREIRA; BRITO, 2018). Na visão dos autores, o FIES foi responsável pela transformação do ensino superior brasileiro em um grande negócio para as empresas (PEREIRA; BRITO, 2018).

O fato de o governo disponibilizar tais recursos a um número crescente de indivíduos que buscam o ensino superior, o torna um incentivador da expansão desse segmento do mercado (PEREIRA; BRITO, 2018). O crescente interesse do mercado financeiro com o setor educacional aponta para uma transformação a educação de um direito para uma mercadoria (PEREIRA; BRITO, 2018). A prioridade governamental em expandir o número de alunos no ensino superior sem se preocupar com a qualidade da formação do estudante seria um equívoco por parte do poder público (PEREIRA; BRITO, 2018).

O artigo de Silva et al (2019) apresentou uma revisão da literatura sobre o PROUNI entre os anos de 2005 e 2018. O artigo apresenta uma conceituação histórica sobre a política pública e a quantidade de bolsas disponibilizadas pelo programa em 2018 (SILVA et al., 2019). Em conclusão, Silva et al indicam que o PROUNI, além de ter promovido um acesso maior dos estudantes da rede pública ao ensino superior, também foi um excelente negócio para as IESP pela renúncia fiscal obtida pelos adeptos ao programa (SILVA et al., 2019).

\section{DISCUSSÃO}

De acordo com Carvalho (2006) e Souza e Menezes (2014), a Reforma Universitária de 1968 foi um marco para a expansão do ensino superior privado no Brasil. Para elucidar o impacto da Reforma Universitária e do ano de 1968 para o segmento da medicina, o estudo de Oliveira et al (2019) mostrou que, entre 1808 e 2018, a relevante expansão do ensino médico no Brasil ocorreu, principalmente, nos períodos dos governos militares até Sarney (1964 a 1988), intensificaram-se nos governos de Fernando Henrique Cardoso (1989 a 1994) e Luís Inácio Lula da Silva (2003 a 2010), mas atingiram o pico dessa expansão após 2014, com a implementação do Programa Mais Médicos em 2013 no governo DilmaTemer (2011 a 2018) (HAAS; PARDO, 2017). Somente entre 2011 e 2018 foram inauguradas mais escolas de ensino médico $(\mathrm{n}=119)$ do que as que foram criadas em 194 anos de história do país (1808 a 2002) ( $\mathrm{n}=114$ ) (eMEC, 2018). Atualmente, temos 342 escolas médicas que disponibilizam 35.388 vagas para graduandos de $1^{\circ}$ ano. Do total de cursos médicos, temos $64,9 \%$ de cursos e $73,8 \%$ das vagas na iniciativa privada (ESCOLAS MÉDICAS DO BRASIL, 2020).

Como as IESP podem apresentar mensalidades proibitivos para muitas pessoas, o estudante com dificuldades financeiras pode recorrer ao auxílio do FIES e do PROUNI para arcar com suas despesas educacionais (CHAVES; AMARAL, 2016). Os benefícios são atraentes para as instituições, pois garantem isenção fiscal via PROUNI e menor inadimplência com o FIES. Segundo Haas e Pardo (2017), o valor total que foi deixado de ser arrecadado pelos cofres públicos foi bastante significativo. Para o contexto da IESP estudada, o valor do benefício fiscal superou o investimento realizado pela instituição em bolsas de estudos do PROUNI em 424\%, demonstrando um benefício financeiro ao aderir ao programa (HAAS; PARDO, 2017). Entretanto, Pinto (2016) pauta a relevância de analisar criticamente os benefícios, principalmente o FIES pelo fato de o subsídio ser significativo e haver risco de o empréstimo ser impagável, ocasionando efeitos negativos para os bancos públicos que disponibilizam o recurso. 
A Tabela 2 mostra um levantamento sobre a situação dos contratos do FIES nos cursos mais procurados com a análise dos dados de junho de 2018. Nessa época, de um total de 612.226 contratos em amortização, uma média de 62\% estavam em inadimplência (FNDE, 2018). No mesmo período, o Ministério da Educação (MEC) mostrou 450 mil estudantes inadimplentes, somando o saldo devedor em R $\$ 10$ bilhões $(\mathrm{G} 1,2018)$.

Tabela 2 - Relação do total de contratos do FIES.

\begin{tabular}{|c|c|}
\hline Nome do Curso & $\begin{array}{l}\text { Total de Contratos } \\
\text { em Amortização }\end{array}$ \\
\hline
\end{tabular}

Contratos com atraso a partir de 1 dia

\begin{tabular}{|c|c|c|c|}
\hline DIREITO & 70.100 & $57 \%$ & 40.081 \\
\hline ADMINISTRAÇÃO & 60.307 & $65 \%$ & 39.061 \\
\hline PEDAGOGIA & 38.184 & $74 \%$ & 28.132 \\
\hline ENFERMAGEM & 36.402 & $62 \%$ & 22.712 \\
\hline EDUCAÇÃO FÍSICA & 28.997 & $68 \%$ & 19.654 \\
\hline CIÊNCIAS CONTÁBEIS & 27.770 & $59 \%$ & 16.299 \\
\hline $\begin{array}{c}\text { GESTÃO DE RECURSOS } \\
\text { HUMANOS }\end{array}$ & 24.386 & $77 \%$ & 18.684 \\
\hline ENGENHARIA CIVIL & 23.531 & $53 \%$ & 12.513 \\
\hline PSICOLOGIA & 16.950 & $56 \%$ & 9.509 \\
\hline FISIOTERAPIA & 15.947 & $61 \%$ & 9.673 \\
\hline LOGÍSTICA & 12.878 & $76 \%$ & 9.806 \\
\hline ODONTOLOGIA & 11.508 & $48 \%$ & 5.567 \\
\hline NUTRIÇÃO & 11.169 & $61 \%$ & 6.789 \\
\hline SERVIÇO SOCIAL & 10.945 & $71 \%$ & 7.817 \\
\hline FARMÁCIA & 10.689 & $50 \%$ & 5.346 \\
\hline $\begin{array}{l}\text { ENGENHARIA DE } \\
\text { PRODUÇÃO }\end{array}$ & 10.262 & $57 \%$ & 5.814 \\
\hline MEDICINA & 9.258 & $32 \%$ & 2.934 \\
\hline $\begin{array}{c}\text { ARQUITETURA E } \\
\text { URBANISMO }\end{array}$ & 8.757 & $51 \%$ & 4.508 \\
\hline $\begin{array}{c}\text { ANÁLISE E } \\
\text { DESENVOLVIMENTO DE } \\
\text { SISTEMAS }\end{array}$ & 8.098 & $64 \%$ & 5.177 \\
\hline ENGENHARIA MECÂNICA & 8.021 & $51 \%$ & 4.099 \\
\hline BIOMEDICINA & 7.610 & $58 \%$ & 4.393 \\
\hline CIÊNCIAS BIOLÓGICAS & 7.008 & $61 \%$ & 4.255 \\
\hline GASTRONOMIA & 6.961 & $67 \%$ & 4.648 \\
\hline
\end{tabular}

Fonte: Fundo Nacional de Desenvolvimento da Educação, 2018.

Com a recente expansão privada do ensino de Medicina, ocasionada pela Lei do Mais Médicos, torna-se possível a ocorrência de aumento nas taxas de ociosidade nas IESP por se tratar de um curso com mensalidades elevadas, conforme ocorrido no passado (CHAVES; AMARAL, 2016). Vale destacar o grande número de denúncias de fraude nos critérios de inclusão dos estudantes no FIES e a influência de cursos médicos que burlam esse sistema em conluio com estudantes (AGÊNCIA BRASIL, 2019).

Segundo Souza e Menezes (2014) e Pinto (2016), o setor privado de ensino possui alto grau de influência no governo federal, obrigando o Estado a tomar medidas de auxílio em um contexto de contenção de gastos públicos pela implantação da PEC dos Gastos. Tal situação abre espaço para o que 
Carvalho (2006) apelida de “jogo político", podendo ocorrer a suplantação dos interesses públicos pelos particulares.

Embora existam bons cursos médicos privados no Brasil, o ensino médico já sofre questionamentos por conta da sua expansão pelo setor privado (SCHEFFER; DAL POZ, 2015). Na avaliação dos resultados do último Exame Nacional do Desempenho dos Estudantes (ENADE) dos cursos de Medicina, que é trienal, em 2016, o desempenho dos estudantes concluintes, avaliado pelo Conceito Enade $\geq 4$ foi de 57\% nas públicas contra 19\% nas privadas (INEP, 2016), como mostrado na Tabela 3.

Tabela 3 - Distribuição percentual dos conceitos em 75 IES públicas e 101 IES privadas nos cursos de Medicina no ENADE 2016.

\begin{tabular}{lccccc} 
& Conceito 1 & Conceito 2 & Conceito 3 & Conceito 4 & Conceito 5 \\
\hline ENADE Pública & $0,00 \%$ & $8,00 \%$ & $34,67 \%$ & $53,33 \%$ & $4,00 \%$ \\
\hline ENADE Privada & $6,93 \%$ & $23,76 \%$ & $50,50 \%$ & $18,81 \%$ & $0,00 \%$
\end{tabular}

Fonte: INEP, 2016.

De acordo com Souza e Menezes (2014), um dos motivos que ocasionam a falta de qualidade das IESP brasileiras é a priorização do lucro em detrimento da qualidade, sem perspectivas de reduzi-lo para investimento em melhora no ensino. Para equacionar os custos com os novos métodos de ensino e o lucro desejado pelo sistema privado, as IESP podem adotar a estratégia de reduzir salários dos docentes. Segundo Trelha et al (2008), os salários dos professores é o fator principal para o elevado custo do ensino de Medicina. Entretanto, a redução dos salários pode desestimular bons professores ou resultar na contratação de docentes menos graduados academicamente, culminando com queda na qualidade do ensino oferecido.

Outro ponto de preocupação para a educação médica é o baixo interesse das IESP com a realização de pesquisas. O financiamento governamental incentiva a formação de instituições com interesses desassociados da investigação científica (CHAVES; AMARAL, 2016). Salvo exceções, as IESP não promovem a interligação do ensino, da pesquisa e da extensão, sendo que $81,2 \%$ dos estudantes de pós-graduação strictu sensu estudavam em instituições públicas em 2014. A pós-graduação é o principal elo entre ensino, pesquisa e extensão e o incentivo ao setor privado de ensino resulta em um número maior de jovens em um ambiente de formação desprovidos de tal articulação (CHAVES; AMARAL, 2016).

O investimento em propostas de escolas médicas com currículos não apenas orientados, mas também baseados na comunidade, e com ênfase na atenção primária à saúde, deve ser fortemente incentivado, visando à verdadeira transformação das realidades locais. Entretanto, para viabilizar esse tipo de currículo é necessária uma permanente capacitação docente e muito mais tempo de planejamento do que execução das atividades didáticas com uso de metodologias ativas. Essas horas consideradas horas-aula e, portanto, não são remuneradas pelos cursos privados. Nos cursos públicos, pesquisa representa maior peso na progressão da carreira docente, sendo que o ensino não tem peso significativo. Por esses motivos, poucas transformações têm ocorrido no ensino médico brasileiro, a não ser inovações pontuais (OLIVEIRA; LIMA; PEREIRA JÚNIOR, 2019).

Uma alternativa cada vez mais buscada por estudantes brasileiros é realizar o curso de Medicina em países vizinhos, devido à menor concorrência e mensalidades mais baratas, principalmente Paraguai, Bolívia e Argentina. Nas faculdades desses países, as mensalidades são mais baixas (variam de $\mathrm{R} \$ 700$ a R \$ 2 mil) e o ingresso no curso é muito mais fácil (quase nenhuma das instituições realiza vestibular) (ISTO É, 2019). Como resultado dessa procura, proliferaram cursos de Medicina em cidades da fronteira com o Brasil, estimando-se que haja mais 65 mil brasileiros estudando atualmente em IESP dos países circunvizinhos (JORNAL H2FOZ, 2019).

Em geral, as informações sobre a qualidade da formação profissional são muito ruins, tendo em vista a extensa carga horária presencial e precários estágios práticos que não comportam a quantidade excessiva de graduandos (ISTO É, 2019). O resultado disso é a baixíssima aprovação dos egressos desses 
cursos na prova de revalidação dos diplomas (Revalida) realizada pelo Instituto Nacional de Pesquisas Educacionais Anísio Teixeira (INEP), mesmo sendo uma prova de dificuldade moderada a baixa (INEP, 2020; CFM, 2020).

\section{CONCLUSÃO}

Os achados da revisão demonstram a importância do auxílio financeiro governamental para a redução da taxa de ociosidade nas IESP, provocando dependência do setor privado ao público, e o incentivo para a expansão do segmento na educação superior. O objetivo primário de várias IESP é o lucro, desprestigiando investimentos no ensino se esses resultarem em impactos negativos nos resultados financeiros das instituições.

Para o ensino de Medicina, a expansão das IESP é um motivo de alerta, pois muitas oferecem ensino de qualidade questionável e podem afetar a prestação de serviços médicos à população no futuro. Com o aumento nos custos do ensino médico por conta da necessidade cada vez maior da utilização de simuladores, pagamento de locais de estágio em serviços de saúde conveniados, remuneração de preceptores docentes e não docentes, a formação médica corre riscos, pois, uma vez que as IESP tendem a preservar o lucro, provocam impactos diretos na qualidade da educação do estudante. Os custos crescentes e o congelamento dos gastos públicos para os próximos vinte anos com a Emenda Constitucional $\mathrm{n}^{\circ}$ 95, podendo limitar o auxílio governamental, tendem a colocar algumas IESP de Medicina em uma situação administrativa delicada.

Com os cursos públicos em Medicina possuindo altíssima concorrência nos vestibulares e do alto custo das mensalidades nos cursos privados, que são a maioria, tendo em vista a expansão de cursos de graduação médica ocorrida nessa última década, muitas famílias brasileiras investem na formação de seus filhos em cursos de baixíssima qualidade, principalmente em países circunvizinhos, criando o dilema da revalidação dos diplomas para conseguirem o registro profissional e atuarem como médicos no país. Esse ciclo vicioso nefasto para a qualidade da formação médica cria uma série de distorções, muitas vezes mal entendidas, e culpam-se os dispositivos essenciais de controle da formação médica para atendimento de qualidade à população brasileira, como o Revalida e a necessária avaliação dos egressos das escolas médicas brasileiras, públicas e privadas, que também devem ter a avaliação da qualidade da formação, de preferência com os mesmos instrumentos.

\section{REFERÊNCIAS}

AGÊNCIA BRASIL. PF deflagra operação para coibir fraudes do Fies no interior paulista. 2019. Disponível em: https://agenciabrasil.ebc.com.br/geral/noticia/2019-09/pf-inicia-acao-para-coibirfraudes-em-universidades-no-interior-de-sp. Acessado em 09 de agosto de 2020.

BRANDÃO, Caroline Felipe Soares; CARVALHO-FILHO, Marco Antônio; CECILIOFERNANDES, Dario. Simulation centers and pedagogical planning: Two sides of the same coin. Scientia Medica, v. 28, n. 1, p. 1-7, 2018. DOI: 10.15448/1980-6108.2018.1.28709

BRASIL. Emenda Constitucional n ${ }^{\circ}$ 95, de 15 de dezembro de 2016. Altera o Ato das Disposições Constitucionais Transitórias, para instituir o Novo Regime Fiscal, e dá outras providências. Diário Oficial da União - Seção 1 - 16/12/2016, Página 2

BRASIL. Lei n ${ }^{\circ}$ 10.260, de 12 de Julho de 2001. Dispõe sobre o Fundo de Financiamento ao Estudante do Ensino Superior e dá outras providências. Diário Oficial da União - Seção 1 - Eletrônico 13/7/2001, Página 2.

BRASIL. Lei $\mathrm{n}^{\circ}$ 11.096, de 13 de janeiro de 2005. Institui o Programa Universidade para Todos PROUNI, regula a atuação de entidades beneficentes de assistência social no ensino superior; altera a Lei $\mathrm{n}^{\mathrm{o}}$ 10.891, de 9 de julho de 2004, e dá outras providências. Diário Oficial da União - Seção 1 14/1/2005, Página 7. 
CARVALHO, Cristina Helena Almeida. O PROUNI no governo Lula e o jogo político em torno do acesso ao ensino superior. Educação \& Sociedade, v. 27, n. 96, p. 979-1000, 2006. DOI: 10.1590/S0101-73302006000300016.

CFM - Conselho Federal de Medicina. CFM reitera, em vídeo, defesa da aprovação no Revalida como critério para que formado em medicina no exterior possa atuar no Brasil. 2020. Disponível em: https://portal.cfm.org.br/index.php?option=com_content\&view $=$ article\&id=28725:2020-06-24-2228-59\&catid=3 Acessado em 02 de agosto de 2020.

CHAVES, Vera Lúcia Jacob. Política de financiamento e a expansão da educação superior no Brasil: o público e o privado em questão. Educação temática digital, v. 17, n. 2, p. 427-441, 2015. DOI: 10.20396/etd.v17i2.8635212

CHAVES, Vera Lúcia Jacob; AMARAL, Nelson Cardoso. Política de expansão da educação superior no Brasil - O PROUNI e o FIES como financiadores do setor privado. Educação em revista, v. 32, n. 4, p. 49-72, 2016.

COSTA, Danielle Dias; FERREIRA, Norma-Iracema Barros. O PROUNI na educação superior brasileira: indicadores de acesso e permanência. Avaliação (Campinas), v. 22, n. 1, p. 141-163, 2017. Doi: 10.1590/s1414-40772017000100008.

DAL POZ, Mário Roberto; COUTO, Maria Helena Costa; FRANCO, Thais Andrade Vidaurre. Inovação, desenvolvimento e financiamento das instituições de Ensino Superior em saúde. Cadernos de Saúde Pública, v. 32, supl. 2, e00139915, 2016. DOI: 10.1590/0102-311X00139915

e-MEC. Cadastro e-MEC de Instituições e Cursos de Educação Superior. Disponível em: http://emec.mec.gov.br/ Acesso em: 30 de novembro de 2018.

ESCOLAS MÉDICAS NO BRASIL. Todas as escolas médicas. 2020. Disponível em: https://www.escolasmedicas.com.br/escolas-medicas-todas.php Acessado em 02 de agosto de 2020.

FNDE - FUNDO NACIONAL DE DESENVOLVIMENTO DA EDUCAÇÃO. Portal da transparência. Aceso à informação (Detalhamentos sobre FIES Detalhamentos sobre FIES - Protocolo 23480013306201811). Brasília: Portal da transparência, 2018.

G1. Inadimplência gerou uma dívida de R\$ 10 bilhões no Fies, diz MEC. 2018. Disponível em: https://g1.globo.com/educacao/noticia/inadimplencia-gerou-uma-divida-de-r-10-bilhoes-no-fies-dizmec.ghtml. Acessado em 28 de agosto de 2020.

H2FOZ. Incerteza e angústia: a situação dos brasileiros que estudam Medicina no Paraguai. 2019. Disponível em: https://www.h2foz.com.br/noticia/incerteza-e-angustia-a-situacao-dos-brasileiros-queestudam-medicina-no-paraguai Acessado em 02 de agosto de 2020.

HAAS, Celia Maria; PARDO, Rosangela Silva. Programa Universidade para Todos (PROUNI): efeitos financeiros em uma instituição de educação superior privada. Avaliação (Campinas), v. 22, n. 3, p. 718740, 2017. DOI: $10.1590 /$ s1414-40772017000300008.

INEP - INSTITUTO NACIONAL DE ESTUDOS E PESQUISAS EDUCACIONAIS ANÍSIO TEIXEIRA. Exame Nacional de Revalidação de Diplomas Médicos Expedidos por Instituição de Educação Superior Estrangeira (Revalida). Disponível em: http://portal.inep.gov.br/web/guest/educacao-superior/revalida Acessado em 02 de agosto de 2020.

INEP - INSTITUTO NACIONAL DE ESTUDOS E PESQUISAS EDUCACIONAIS ANÍSIO TEIXEIRA. Relatório síntese de área medicina no exame nacional de desempenho dos estudantes. Disponível em: http://download.inep.gov.br/educacao_superior/enade/relatorio_sintese/2016/medicina.pdf Acessado em 02 de agosto de 2020. 
ISTOÉ. 65 mil brasileiros se aventuram para cursar Medicina em países vizinhos. 2019. Disponível em: https://istoe.com.br/65-mil-brasileiros-se-aventuram-para-cursar-medicina-em-paises-vizinhos / Acessado em 02 de agosto de 2020.

JOANNA BRIGGS INSTITUTE - Methodology for JBI Scoping Reviews. 2020. Disponível em: https://reviewersmanual.joannabriggs.org/display/MANUAL/Chapter+11\%3A+Scoping+reviews.

Acesso em: 15 de junho de 2019.

MCCOWAN, Tristan. Expansion without equity: An analysis of current policy on access to higher education in Brazil. Higher Education, v. 53, n. 1, p. 579-598, 2007.

NASSAR, Leonardo Maso; PEREIRA JÚNIOR, Gerson Alves. Custos do ensino de medicina no Brasil: uma revisão sistematizada da literatura. Revista de Administração Hospitalar e Inovação, 16, n. 3, p 85-98, 2019.

OLIVEIRA, Bruno Luciano Carneiro Alves; LIMA, Sara Fiterman; PEREIRA, Mariana Uchoa Lopes; PEREIRA JÚNIOR, Gerson Alves. Evolução, distribuição e expansão dos cursos de medicina no Brasil (1808-2018). Trabalho, Educação e Saúde, v. 17, n. 1, e0018317, 2019. DOI: 10.1590/1981-7746sol00183.

PEREIRA, Tarcísio Luís; BRITO, Silvia Helena Andrade de. The expansion of private higher education in Brazil through FIES. ECCOS - Revista Científica, v. 47, n. 1, p. 337-354, 2018.

PINTO, José Marcelino de Resende. Uma análise da destinação dos recursos públicos, direta ou indiretamente, ao setor privado de ensino no Brasil. Educação \& Sociedade, v. 37, n. 134, p. 133-152, 2016. DOI: 10.1590/ES0101-73302016157682.

SCHEFFER, Mário César; DAL POZ, Mário Roberto. The privatization of medical education in Brazil: Trends and challenges. Human Resources for Health, v. 13, n. art. Nº 96, 2015. DOI: 10.1186/s12960015-0095-2

SILVA, Eduardo Reis; BELFORT, Camila Raquel Nunes; SILVA, Thiago Sousa; SILVA, Wagner Vinícius Oliveira; MACEDO, Maíra Aassunção; ANDRADE, Gabriela Paula. Governmental public policy: a study about the university for all program- PROUNI 2005 to 2018. Humanidades e Inovação, v. 6, n. 9, p. 187-216, 2019.

SOUZA, Márcio Rodrigo de Araújo; MENEZES, Monique. Programa Universidade para Todos (PROUNI): quem ganha o quê, como e quando? Ensaio: Avaliação e Políticas Públicas em Educação, v. 22, n. 8, p. 609-634, 2014. DOI: 10.1590/S0104-40362014000300003.

TRELHA, Celita Salmaso; CASARIM, Luís Fernando; ALMEIDA, Marcio José; GORDAN, Pedro Antônio. Cursos de Medicina com currículos inovadores são mais caros? Análise de custos do Curso Integrado de Graduação em Medicina da Universidade Estadual de Londrina. Revista brasileira de educação médica, v. 32, n. 2, p. 160-173, 2008

Submetido: $10 / 09 / 2020$

Aprovado: $17 / 12 / 2020$ 